\title{
Authors' reply to Olfson and Schoenbaum, Nardo, Bartlett, Moore, Case, Gotzsche, and Barber and colleagues
}

\section{Citation}

Lu, C. Y., G. Simon, and S. B. Soumerai. 2014. "Authors' Reply to Olfson and Schoenbaum, Nardo, Bartlett, Moore, Case, Gotzsche, and Barber and Colleagues." BMJ 349 (oct09 16) (October 9): g5722-g5722. doi:10.1136/bmj.g5722.

\section{Published Version}

doi:10.1136/bmj.g5722

\section{Permanent link}

http://nrs.harvard.edu/urn-3:HUL.InstRepos:32692584

\section{Terms of Use}

This article was downloaded from Harvard University's DASH repository, and is made available under the terms and conditions applicable to Other Posted Material, as set forth at http:// nrs.harvard.edu/urn-3:HUL.InstRepos:dash.current.terms-of-use\#LAA

\section{Share Your Story}

The Harvard community has made this article openly available.

Please share how this access benefits you. Submit a story.

\section{Accessibility}




\title{
Authors' reply to Olfson and Schoenbaum, Nardo, Bartlett, Moore, Case, Gøtzsche, and Barber and colleagues
}

\author{
Christine Y Lu instructor ${ }^{1}$, Gregory Simon senior investigator ${ }^{2}$, Stephen B Soumerai professor ${ }^{1}$ \\ ${ }^{1}$ Department of Population Medicine, Harvard Medical School and Harvard Pilgrim Health Care Institute, Boston, MA, USA; ${ }^{2}$ Group Health Research \\ Institute, Seattle, WA, USA
}

We agree with Olfson and Schoenbaum about the need for more systematic use of cause of injury codes. ${ }^{12}$ Public health efforts to understand and reduce suicide risk depend on accurate data. Indeed, this problem (varying use of these codes across and within health systems over time) motivated us to use a proxy measure for suicide attempts.

Several comments question the sensitivity of this proxy measure (the proportion of suicide attempts by psychotropic drug poisoning). ${ }^{3-5}$

Olfson and Schoenbaum cite US national data that sensitivity is likely to be no more than $50 \%$. The use of these data is, however, problematic given the inconsistent use of cause of injury codes. We examined this question in three of our research network health systems where these codes are used regularly. We found that the proportion of suicide attempts (by cause of injury code) across age groups and health systems ranged from roughly $30 \%$ to $60 \%$. A sensitivity of $30 \%$ to $60 \%$ means that this proxy measure would not be appropriate for estimating prevalence, and reduced sensitivity would reduce statistical power for detecting changes over time, although it would not bias our interrupted time series analysis.

Olfson and Schoenbaum also say that only a small proportion of emergency department visits for poisoning entail psychotropic drugs. Their data, however, concern intentional poisoning (poisoning by someone else) rather than self inflicted poisoning (intentional overdose).

More important for our study is the question of positive predictive value - the proportion of psychotropic poisonings that are intentional overdoses according to cause of injury code. We also examined this question in three of our member health systems where these codes are used regularly. Positive predictive values ranged from $35 \%$ to $80 \%$ across health systems and age groups, and from $62 \%$ to $80 \%$ in adolescents, the group of greatest interest.
Nevertheless, we acknowledge that psychotropic poisoning is an imperfect proxy for suicide attempts and that its use might reduce the sensitivity of our methods. But this proxy measure is preferable to cause of injury codes in settings where code usage varies over time (thereby precluding valid time series analysis).

In the evaluation of policies or regulatory changes (such as the antidepressant safety warnings), true experiments or randomised trials are usually not possible. We agree with Olfson and Schoenbaum that quasi-experimental or observational studies are open to varying interpretation. In support of our interpretation, we emphasise two points.

Firstly, our study question and methods were specified in advance.

Secondly, our results do not indicate a gradual trend in rates of antidepressant use or psychotropic drug poisonings but a discontinuity or change in slope at a time (specified a priori) corresponding to the Food and Drug Administration (FDA) warnings and related publicity. We stand by our conclusion that these warnings, however well intentioned, seem to have had unintended effects.

We considered the stratified analysis proposed by $\mathrm{Case}^{6}$ but decided it would not be valid. Rates of antidepressant use decreased considerably after the warnings, and it is reasonable to presume that this reduction was not random. If, for example, decreased antidepressant use was concentrated among those with less severe depression, this would bias any comparison that was limited to either antidepressant users or non-users.

Gøtzsche's comments focus on our inability to directly address clinical questions about the efficacy and safety of antidepressants in young people. ${ }^{7}$ We agree. A policy evaluation study cannot directly answer efficacy and safety questions that should be investigated by randomised trials. But the opposite also holds. Randomised trials to evaluate efficacy and safety cannot 
accurately predict the consequences of policy or regulatory decisions. Of note, meta-analyses of randomised trials of antidepressants did not examine effects on suicide attempts, only on a broad category of "suicidal ideation or behaviours." But even if trials showed that antidepressants increased the risk of suicide attempts in young people, it does not necessarily imply that a warning from the FDA would reduce this risk. Our data do not indicate that the warning reduced the risk of suicide attempts in adolescents and young adults.

Discontinuities or abrupt reductions in antidepressant prescriptions, which were consistent with previously published articles, suggest changes in patient care after the FDA warnings. Importantly, these studies found substantial reductions in antidepressant use and no compensating increases in the use of treatment alternatives among young people after the warnings. Our interpretation that the warnings may be associated with undertreatment of mood disorders among young people is based on all of these data, not reduced antidepressant use alone. In addition, sudden changes in patient care may have negative effects. Our data certainly do not indicate that the FDA warnings reduced suicidal behaviour in adolescents and young adults. Adults who were not targeted by the warnings ("comparison" group) had smaller reductions in antidepressant use, and other studies found compensating increases in use of treatment alternatives. There was no change in suicidal behaviour among adults. Given limited research funding, we focused on three outcome measures and did not measure reductions in depression diagnoses over time, which have already been shown in other studies of our network of US health plans.

We considered the additional national data provided by Barber and colleagues. ${ }^{8}$ However, data on self harm from WISQUARS-non-fatal emergency department visits (ages 10-17) seem to show spikes in years 2004 and 2005, which coincided with the timing of the FDA warnings, but without longer baseline data and appropriate statistical analysis we could not draw definitive conclusions. Our figure on completed suicides in adolescents shows a similar pattern to that of Barber and colleagues, which is based on the CDC WISQARS-fatal website. We are not aware that measures from the youth risk behaviour survey have been validated.

Finally, the most important implication of our study is the need for better risk communication of serious drug warnings through improved coordination between the lay press and the FDA. This should include more holistic consideration of both non-drug and drug treatments and their benefits and risks for evidence based patient care.

Competing interests: GS has received research grants from Otsuka Pharmaceuticals.

Full responses at: www.bmj.com/content/348/bmj.g3596/rr/702921 and www.bmj.com/content/348/bmj.g3596/rr/761177.

1 Lu CY, Zhang F, Lakoma MD, Madden JM, Rusinak D, Penfold RB, et al. Changes in antidepressant use by young people and suicidal behavior after FDA warnings and media coverage: quasi-experimental study. BMJ 2014;348:g3596. (18 June.)

2 Olfson M, Schoenbaum M. Link between FDA antidepressant warnings and increased suicide attempts in young people is questionable. BMJ 2014;349:95614.

3 Nardo JM. Impossible to draw meaningful conclusions from study of changes in antidepressant use after FDA warnings. BMJ 2014;349:g5643.

4 Bartlett RO. Proxy for suicide attempts was inappropriate in study of changes in antidepressant use after FDA warnings. BMJ 2014;349:g5644.

5 Moore TJ. Antidepressants increase, rather than decrease, risk of suicidal behaviours in younger patients. BMJ 2014;349:g5626.

6 Case BG. More data needed to interpret link between suicide and FDA warning on antidepressants. BMJ 2014;349:g5616.

7 Gøtzsche PC. Study of study of changes in antidepressant use after FDA warnings is not Gøtzsche PC. Study of study of char
reliable. BMJ 2014;349:g5623.

8 Barber C, Azrael D, Miller M. Study findings on FDA antidepressant warnings and suicide attempts in young people: a false alarm? BMJ 2014;349:95645.

Cite this as: BMJ 2014;349:95722

๑ BMJ Publishing Group Ltd 2014 